\title{
Unusual Bromination of 9-Cyano-10-methylacridan
}

\author{
In-Sook Han Lee and Chang Kiu Lee ${ }^{\dagger}$

\begin{abstract}
Deparment of Science Education, Kangwon National Chiversin, Chuncheon 200-701, Korea. ${ }^{*}$-mail: ishlokangw'on ackr 'Department of Chemistry, Kangw'on National Wniversit, Chuncheon 200-701. Korea

Received Februarv 22. 2007
\end{abstract}

Key Words : Acridinium cation, Aromatic bromination. Tribronide

Acridinium cations have been widely studied due to their broad application especially in the area of chemiluminescence. 1: 9-Cyano-10-methylacridinium ions (cf. 2) are particularly important because of their chemiluminescent properties as well as their interesting chemical behavior. The 9-position of the cation is susceptible to nucleophilic addition. Furthermore the cation is a good hydride acceptor and has been employed as a $\mathrm{NAD}^{-}$analogue for hydride transfer reaction. ${ }^{4.5}$

As a part of our studies on the mechanism of hydride transfer reaction between $\mathrm{NAD}^{-}$analogues. we were interested in the preparation of 9-cyano-10-methylacridinium bromide (2a). One of the strategies is the oxidation of 9cyano-10-methylacridan (1) with dilute nitric acid ${ }^{6}$ and subsequent exchange of the hydrogen dinitrate counterion with bromide ion. A polarographic study has been reported for the oxidation of 1 by $\mathrm{LiNO}_{2}$ but its application for preparation of the acridinium salt is not certain. ${ }^{7}$ Direct oxidation of 1 by bromine in $\mathrm{CCl}_{4}$ seemed to be straightforward although the yield of 2a was low $(47 \%) .51$ order to improve the yield we came to examine the reaction conditions for the conversion of 1 to $2 \mathrm{a}$ by bromine (Scheme 1).

When a suspension of 1 in absolute ethanol was treated with an excess amount of bromine. a tribromide $2 \mathrm{~b}$. not monobromide 2 a. was fomed. However. when an attempt was made to recrystallize the crude reaction product from ethanol-water $(9: 1 . \mathrm{v} / \mathrm{y})$ mixture by heating to dissolve the solid. white needles were obtained within a few min. The solid was found to be 2.7-dibromo-10-methyl-9(10H)-acridone (3). This is quite an unusual kind of reaction because both oxidation of the acridinium cation to acridone and aromatic bromination took place in one-port reaction. Furthermore. the source of the bromine was the tribromide ion in 2b.

The compound 3 was reported to be prepared by methylation of the corresponding $\mathrm{N}-\mathrm{H}$ compound $6{ }^{89}$ which in turn. was prepared by bromination of $9(10 H)$-acridone (5). Direct bromination of 10 -methyl- $9(10 H)$-acridone (4) with bromine in boiling acetic acid also gave 3 .

We have ruled out that 10 -methyl-9(10H)-acridone (4) was involved as an intermediate because the compound 3 could not be obtained upon treating 4 with bromine and/or $\mathrm{KBr}$ in ethanol-water $(9: 1, v / v)$ solution. Furthemore. bromination is unlikely to take place in the first step from 1 . because 2b was successfully prepared from 1 and purified by washing with isopropyl alcohol-water $(4: 1, v / v)$ followed by $\mathrm{CH}_{2} \mathrm{Cl}_{2}$. The correct elemental analysis of $\mathbf{2 b}$ with three bromine atoms was obtained. Oxidation of 1 with iodine under similar condition was unsuccessful and the starting material was recovered.

Although the mechanism for the transformation of $\mathbf{2 b}$ to $\mathbf{3}$ is uncertain. we propose a mechanisn in which the tribromide ion is involved in Scheme 2. Once the nucleophilic addition of the negatively-charged bromine atom at the center of $\mathrm{Br}_{2}{ }^{-}$to $\mathrm{C}-9$ of the cation takes place to form I a sixmembered transition state may be achieved so that the bromine atom at the side can be transferred to $\mathrm{C}-2$ of the acridine ring (cf. II). The monobromoacridinium intermediate IV. once fonmed. may undergo similar steps introducing the second bromine atom at C-7 to give $\mathbf{V}$. Due to the<smiles>CC1c2ccccc2N(C)c2ccccc2C1C</smiles><smiles>[X]c1cccc2c(C#N)c3ccccc3[n+](C)c12</smiles>

2a, $\mathrm{X}=\mathrm{Br}$, $2 \mathrm{~b}, \mathrm{X}=\mathrm{Br}_{3}$

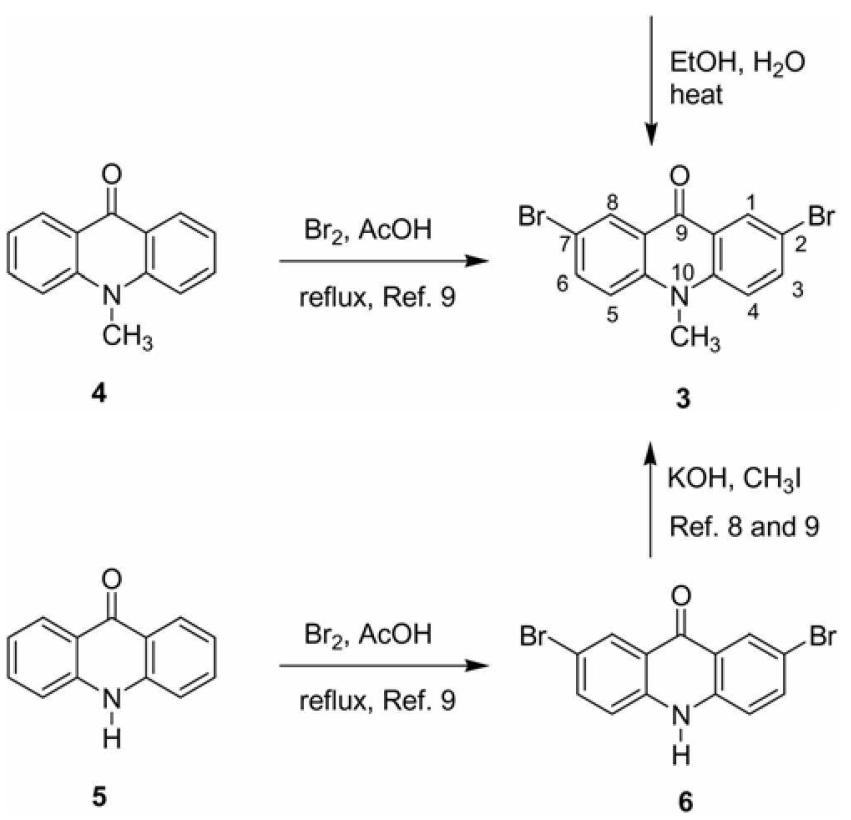

Scheme 1 
<smiles>C[n+]1cc(C#N)c(C=[Bi]Br)c2ccccc21</smiles>

$2 b$<smiles>CC1(N)c2cc(Br)ccc2[N+](C)(C)c2ccc(Br)cc21</smiles>

V

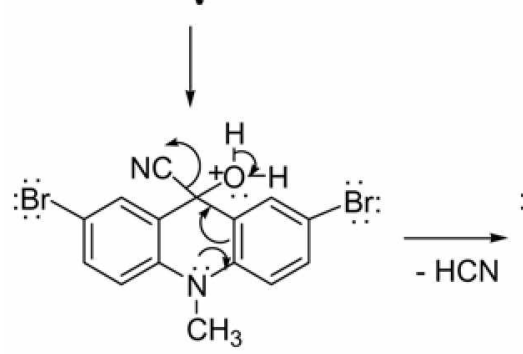

VI<smiles></smiles>

I<smiles>C[N+]1(C)c2ccccc2C(Br)(C#N)C1(Br)C(Br)Br</smiles>

II<smiles>Cn1c2ccccc2c2cc(Br)ccc21</smiles>

III

IV<smiles></smiles>

VII<smiles>Cn1c2ccc(Br)cc2c(=O)c2cc(Br)ccc21</smiles>

3

Scheme 2

presence of the two bromine atoms the intermediate $\mathbf{V}$ should be more reactive than $\mathbf{2 b}$ itself. and the nucleophilic addition of $\mathrm{H}_{2} \mathrm{O}$ should be possible to form VI. Loss of $\mathrm{HCN}$ from VI and subsequent loss of $\mathrm{H}^{+}$from VII should give 3 . The mechanism for the transformation of 9-cyano-10methylacridinium cation (like $2 \mathrm{a}$ ) to + by $\mathrm{H}_{2} \mathrm{O}_{2}$ in alkaline solution or by aqueous $\mathrm{NaOH}$ has been reported. ${ }^{1-3}$

Although the dibromoacridones 6 and 3 were reported in literature. ${ }^{8.5}$ the positions of the bronine atoms are ambiguous. We have established the structures of $2 \mathrm{~b}$ and $3 \mathrm{by}$ spectroscopic methods in addition to elemental analyses. The presence of 9-acridone skeleton in 3 was confirmed by the peak at $1636 \mathrm{~cm}^{-1}$ in the IR spectrum, which was shifted to quite low frequency for a carbonyl stretch. ${ }^{1 /}$ The peak at $174.42 \mathrm{ppm}$ in ${ }^{13} \mathrm{C}$ spectrum also supports the carbonyl group. The presence of two bromine atoms on the aromatic ring was readily evidenced by the typical mass spectral peaks at $m z 365$ (relative intensity 53\%). $367(100 \%$ ). and $369(56 \%)$, which correspond to $\mathrm{M}^{-}, \mathrm{M}^{+}+2$, and $\mathrm{M}^{-}+4$. respectively. Similar mass spectral data were reported for 3 with relative intensities of $54 \%, 100 \%$ and $41 \%$. respectively. ${ }^{11}$

The positions of bromine in 3 were established by the analysis of the NMR spectra. ${ }^{\text {} H}$-NMR spectrum showed three signals in the aromatic region, indicating that the molecule is symmetric. The peak at $\delta 8.36$ corresponding to $\mathrm{C}-\mathrm{l}-$ and $\mathrm{C}-8-\mathrm{H}$ should appear farthest down field because the protons are flanked by both carbonyll and bromine. It is a 2-proton doublet having $J=2.2 \mathrm{~Hz}$ which is a reasonable meta coupling constant. The peak at $\delta 8.00$ appearing as a $2-$ proton doublet of doublets has meta $(2.2 \mathrm{~Hz})$ and ortho $(9.6$ $\mathrm{Hz}$ ) coupling constants. This should be due to the $\mathrm{C}-3-$ and C-6-H. The 2- proton doublet at d 7.84 with $J=9.6 \mathrm{~Hz}$ corresponds to the $\mathrm{C}-4$ - and $\mathrm{C}-5-\mathrm{H}$. The relative chemical shift values are in consistent with the calculated values using 2-amino-5-bromoacetophenone or similar types of conpounds as a model. ${ }^{12}$ Substitution at the 3-and 6-positions may be possible. but then the values of the chemical shift and coupling constant do not fit well.

In conclusion. we report a quite unusual bromination of an acridine derivative which leads the fonmation of 2.7-dibromo-10-methyl-9(10H)-acridone.

\section{Experimental Section}

Melting points were determined on a Fisher MEL-TEMP apparatus and were uncorrected. IR and UV-visible spectra were recorded on Perkin-Elmer 283 and Cary 14 spectrophotometers. respectively. NMR spectra were recorded on a Bnuker DPX-400 FT NMR spectrometer in the Central Lab of Kangwon National University at $400 \mathrm{MHz}$ for ${ }^{1} \mathrm{H}$ and 100 $\mathrm{MH} \angle$ for ${ }^{13} \mathrm{C}$ and were referenced to tetramethylsilane. Mass spectra were obtained on a AEI MS-30 mass spectrometer. Elemental analyses were performed by $\mathrm{M}-\mathrm{H}-\mathrm{W}$ Laboratories. Phoenix, Arizona. USA.

9-Cyano-10-methylacridinium Tribromide (2b). To an 
ice-cold solution of $3.00 \mathrm{~g}$ ( 13.64 mmole) of 1 which was prepared by a literature method ${ }^{13}$ in absolute ethanol $(400$ $\mathrm{mL}$ ) was added an excess amount of bromine $(\mathrm{ca} .2 \mathrm{~mL})$. Soon a fine orange precipitate formed which was collected by filtration, washed with $50 \mathrm{~mL}$ of isopropyl alcohol-water $(4: 1, v / v)$ and subsequently with dichloromethane $(2 \times 50$ $\mathrm{mL}$ ). The solid was dried under vacuum to give $2 \mathrm{~b} .3 .85 \mathrm{~g}$ $(90 \%)$. mp $210^{\circ} \mathrm{C}$; IR (KBr) 3420 w. 3010 w. $1630 \mathrm{ml} .1610$ s, $1543 \mathrm{~s}, 1458 \mathrm{~s} .1380 \mathrm{~s} .1295 \mathrm{~m} .1275 \mathrm{~m}, 1190 \mathrm{~m} .1175 \mathrm{~m}$. 782 s. $760 \mathrm{~m} \mathrm{~cm}^{-1}$; ${ }^{1} \mathrm{H}-\mathrm{NMR}$ (DMSO-d) $\delta 5.02$ (s. $3 \mathrm{H}$. $\left.\mathrm{CH}_{3}\right) .8 .02-9.03\left(\mathrm{~m} .8 \mathrm{H}\right.$, aromatic-H): ${ }^{13} \mathrm{C}-\mathrm{NMR}$ (DMSO- $d_{6}$ ) ppm 40.30. 113.70. 117.51, 120.14, 123.10. 127.25. 130.88. 139.49. 141.47; UV ( $\left.\mathrm{PrOH}-\mathrm{H}_{2} \mathrm{O} .4: \mathrm{I} . \mathrm{v} / \mathrm{v}\right) \lambda_{\max }(\log \varepsilon) 48 \mathrm{I}$ InI (3.45), 45l (3.63). 426 (3.58). $386(4.38) .368(4.06)$. 264 (4.99). Anal. Calcd for $\mathrm{C}_{15} \mathrm{H}_{11} \mathrm{Br}_{3} \mathrm{~N}_{2}$ (458.98): C. 39.25 : H, 2.41: Br, 52.23; N. 6.10. Found: C. 39.10: H, 2.52: Br. $52.49 ;$ N. 5.95 .

2,7-Dibromo-10-methyl-9(10H)-acridone (3). Compound $2 b(8.00 \mathrm{~g})$ was dissolved in ethanol-water $(9: 1 . \mathrm{v} / \mathrm{v} .300$ $\mathrm{mL}$ ) by heating on a steam-bath for a few min. Once the dissolution was complete a white solid of fine needles soon formed. The mixture was cooled and filtered to collect the solid. After washing with absolute ethanol and drying under vacuum. compound 3 was obtained ( $3.60 \mathrm{~g} .76 \%$ ), np 287 ${ }^{\circ} \mathrm{C}$ (lit. ${ }^{\prime 2} 282-283{ }^{\circ} \mathrm{C}$ ): IR (KBr) 3120 w. 3080 w. 2950 w. 2845 w, 1636 m. 1595 s. 1549 m. 1480 s. 1335 s, $1288 \mathrm{~m}$. $1260 \mathrm{ml} .1180 \mathrm{~m}, 1155 \mathrm{~m}, 975 \mathrm{~ms} .920 \mathrm{mss} .822 \mathrm{~s} .808 \mathrm{~m}$ $\mathrm{cm}^{-1} ;{ }^{1} \mathrm{H}-\mathrm{NMR}$ (DMSO-d $\left.d_{6}\right) 83.92\left(\mathrm{~s}, 3 \mathrm{H} . \mathrm{CH}_{3}\right), 7.84$ (d, $2 \mathrm{H}$. 4 - and $\left.5-\mathrm{H} . J_{4,3}=9.6 \mathrm{~Hz}\right), 8.00\left(\mathrm{dd}, 2 \mathrm{H} .3-\right.$ and $6-\mathrm{H}, J_{3.4}=9.6$ $\mathrm{Hz}, J_{3.1}=2.2 \mathrm{~Hz}$ ), 8.36 (d. $2 \mathrm{H}, \mathrm{l}$ - and $8-\mathrm{H}, J_{1.3}=2.2 \mathrm{~Hz}$ ): ${ }^{13} \mathrm{C}-\mathrm{NMR}$ (DMSO- $d_{6}$ ) ppm 34.27. 114.16, 119.40. 122.86. 128.34. 136.72, 141.25. 174.42: UV $(\mathrm{MeOH}) \lambda_{\max }(\log \varepsilon)$ $415 \mathrm{~lm}$ (3.76). 392 (3.74). 281 (4.50), 249 (4.48); MS, $m z$
(\%) $369\left(56, \mathrm{M}^{-}+4\right) .367\left(100, \mathrm{M}^{+}+2\right), 365\left(53 . \mathrm{M}^{-}\right), 354$ (11). $352(21) .350\left(11 . \mathrm{M}^{+} \cdot \mathrm{CH}_{3}\right), 164$ (29). Anal. Calcd for $\mathrm{C}_{14} \mathrm{H}_{0} \mathrm{Br}: \mathrm{NO}(367.05): \mathrm{C} .45 .81 ; \mathrm{H} .2 .47$ : Br. $43.54 ;$ N. 3.82. Found: $\mathrm{C}, 45.60: \mathrm{H}, 2.55 ; \mathrm{Br}, 43.77: \mathrm{N}, 3.80$.

Acknowledgement. This work was supported by Korea Science and Engineering Foundation (R01-2004-10279). We thank Dr. Thomas Robison of $3 \mathrm{M}$ for proof-reading the manuscript.

\section{References}

1. Wroblewska. A.: Huta. O. M.: Midyanyj. S. V.: Patsay: I. O.: Rak. J.: Blazejowski. J. J. Org. Chem. 2004. 69. 1607.

2. Wroblewskia. A.: Huta. O. M.: Patsay. I. O.: Petryshyn. R. S.: Blazejowski, J. Anal. Chim Acta 2004, 507. 229.

3. Happ. J. W. Janzen. E. G.: Rudy, B. J. Org. Chem. 1970. 35.3382

4. Kreevov, M. M.; Lee. I.-S. H. J. Am. Chem. Soc. 1984, 106, 2550

5. Ostovic. D.: Lee. I.S. H.: Roberts. R. M. G.: Kreewoy. M. M. J. Org. Chent 1985.50.4206

6. MeCapra. F.: Richardson. D. G. Tetrahedinon Lett. 1964. 3167

7. Chupakhin, O. N.: Sosonkin, I. M.: Matern. A. I.; Strogov, G. N. Dokl. Ahad. Nawk SSSR 1980. 250,875.

8. Posteseu, I. D.; Suciu, D. J. Prakt. Chem. 1976, 318.515

9. Achesont. R. M.: Robinson. M. T. T. J. Chem. Soc. 1953. 232.

10. (a) Colthup. N. B.: Daly. L. H.: Wiberley. S. E. Introduction to Infrared amd Ramam Sipectroscopl: $2^{\text {nd }}$ ed.: Academic Press: New York. N. Y, 1975, p 283. (b) For 10-methyl-9(10H)-acridone, see Pouchert, C. J. The Aldrich Libray of Infrared Spectra, $2^{\text {nd }}$ ed.; Aldrich Chemical Co. Ine: Milwaukee, Wisconsin. 1985; Vol 2, p 93A.

11. Bowie. J. H.: Cooks. R. G.: Prager. R. H.: Thredgold. H. M. Azst. J. Chem. 1967.20.1179

12. Jackman. L. M.; Sternhell. S. Application of Nuclear Hagnetic Resonance Spectroscopv in Organic Chemistry $2^{\text {nd }}$ ed. Pergamon Press: New York, N. Y.. 1969: p 202.

13. Kaufmant1. C.: Albertin. A. Chem. Ber. 1909. 42.1999. 